\title{
Predicting the probability of Mount Merapi eruption using Bayesian Event Tree_Eruption Forecasting
}

\author{
Dyah Ika Rinawati*, Diana Puspita Sari, Naniek Utami Handayani, and Bramasta Raga Siwi \\ Industrial Engineering Department, Faculty of Engineering, Diponegoro University, Prof. Soedarto, SH Street, Tembalang, Semarang, \\ Indonesia
}

\begin{abstract}
Mount Merapi is one of the active volcanoes in Indonesia that had varied eruption periods from two to eight years. Due to the density of the population living around the slopes of Mount Merapi, its eruptions caused high number of victims. In order to avoid high number of victims, the disaster management should be improved. Disaster management consist of four phases i.e. mitigation, preparedness, response and reconstruction. In disaster mitigation phase, prediction of the Merapi unrest probability is needed. This paper focus on how to predict the probability of Merapi unrest based on volcano-logical information by using Bayesian Event Tree. Bayesian Event Tree (BET) is a probabilistic model that merges all kinds of volcanological information to obtain probability of any relevant volcanic event. The result showed that the probability of Merapi unrest is 0,822 . In the next eruption, it has predicted that the volcanic explosivity index (VEI) 2 was biggest chance with the probability of 0,549 . It showed that the eruption will take place in the main crater of Merapi with the probability of 0,938 .
\end{abstract}

\section{Introduction}

Disaster refers to a "disruption that physically affects a system as a whole and threatens its priorities and goals", Based on the causes, it is possible to distinguish between a natural and man-made disaster. With respect to predictability and speed of occurrence, it is possible to distinguish between a sudden-onset and a slow-onset disaster 1]. Disaster that can be classified in sudden onset are earthquake, tsunami, eruption of volcano, mass movement, flood and storm. While slow onset disaster are epidemic, dryness and extreme temperature.

It is widely known that Indonesia is a country that is passed by the pathway of active volcanoes that is called Ring of Fire. In consequence, Indonesia has 400 volcanoes and 129 of them are active. Therefore, Indonesia is the country with the most active volcanoes where most of them located in Sumatera and Java. Mount Merapi is one of the active volcanoes in Indonesia. The period of the eruption cycle is varied. Merapi's danger level is very high, due to the density of the population living around the slopes of Merapi Mount. The victim died in the eruption of Merapi at 2010 reached 353 peoples. In avoiding the high number of the victims, the disaster management need to be improved. The disaster management consist of four phases, i.e. mitigation, preparedness, response and reconstruction [2]. The mitigation phase refers to rules and mechanisms that reduce social vulnerability. The preparation phase refers to various operations that occur during the period before a disaster strikes. This phase prepare the strategies that allow the implementation of a successful response. The response phase refers to the various operations that are instantly implemented after a disaster strikes. The reconstruction phase refers to operations that conducted in the effect of a disaster.

The mitigation phase is a series efforts to reduce disaster risk, either through physical development as well as awareness and capacity building is facing the threat of disaster. Disaster mitigation is an activity that acts as disaster risk reduction, or efforts made to reduce the victims of the disaster, both fatalities and property. In a volcanic eruption disaster mitigation, risk estimates are required in decision making, especially in land use and management in emergency. According to [3], one of the basic materials science to achieve both of these is the use of reliable and quantitative eruption forecasting. According to [4] eruption forecasting refers to assess the occurrence probability of a given eruptive event, whereas volcanic hazards are normally associated with the analysis of superficial and evident phenomena that usually accompany eruptions (e.g., lava, pyroclastic flows, tephra/ ash fall, lahars, etc.). Nevertheless, several hazards of volcanic origin may occur in non-eruptive phases during unrest episodes. Among others, remarkable examples are gas emissions, phreatic explosions, ground deformation, and seismic swarms. This study aim is predict the Merapi Mount unrest by using Bayesian Event Tree_Eruption Forecasting (BET_EF) in order to help the mitigation phase of disaster management for Merapi eruption.

\footnotetext{
* Corresponding author: dyah.ika@gmail.com
} 


\section{Research Method}

\subsection{Bayesian Event Tree Model}

Eruption forecasting is complicated to do because there are many data and relatively poor knowledge in the eruption process. In contrast with this reality, the extreme risk caused by many volcanoes eruption push to solve this problem. [3]. According to [5], Bayesian statistic is good for forecast the volcano eruption forecasting. Bayesian Event Tree (BET) is a quantitative model for volcanic hazard assessment. BET also offers a short-term and long-term forecast, therefore it can be used in many aspects such as: (1) to compare various types of risk, (2) to analyze the cost / benefit of the risk of mitigation, (3) to show the right land use planning and residential location, and (4) suggesting direct risk reduction like evacuation for people living in a dangerous area [6]. BET represents a development of the method proposed by [7] Marzocchi. BET is probabilistic model that merges all kinds of volcano-logical information from theoretical/empirical models, geological and historical data, and monitoring observations - to obtain probability of any relevant volcanic event. Such probabilities represent a homogeneous and quantitative synthesis of the present knowledge about the volcano [4]. In general, BET does not rule out any possibility, but it shapes the probability distribution of the event considered around the most likely outcome accounting for all the information reported above.

This model is based on the event tree concept, which is a graphic representation of every event. Every branch is referring to every step to gain a more specific event and the end of the branch is representation of future event. This Event tree shows all the relevant results that might happen in every volcanoes activity. The point of every branch is named nodes. Here is a node in event tree scheme [3]:

Node 1: shows if there is or there is not a volcano activity in time interval $(\mathrm{t} 0, \mathrm{t} 0+\tau)$, where $\mathrm{t} 0$ is the current time, and $\tau$ is a time window that

Node 2: shows if a volcano activity is caused by magma or something else (for example, hydrothermal, tectonic, etc.)

Node 3: shows that magma will reach the surface (there will be an eruption) or not, in time interval $(\mathrm{t} 0, \mathrm{t} 0+\tau)$

Node 4: shows the location of eruption

Node 5: shows the size of the eruption (for example, Volcanic Eruption Index)

"Node $k$ " indicate one of the possible events of the $k$ th of the event tree. A probability function was attributed at each nodes. For each nodes, there are probability of the conditional events that have been specify, $\left[\theta_{1}{ }^{\text {(unrest) }}\right],\left[\theta_{2}{ }^{(\text {magma })}\right],\left[\theta_{3}{ }^{(\text {erup })}\right],\left[\theta_{4}{ }^{(\text {loc })}\right],\left[\theta_{5}{ }^{(\text {size })}\right]$, where the square brackets stand for a generic "probability density function

(PDF)". Because the first three nodes have only two possible states that are mutually exclusive and exhaustive (unrest and no unrest, magma and no magma, eruption and no eruption), so for simplicity, it has been set, $\left[\theta_{1}{ }^{\text {(unrest })}\right]=\left[\theta_{1}\right],\left[\theta_{2}{ }^{(\text {magma })}\right]=\left[\theta_{2}\right],\left[\theta_{3}{ }^{(\text {erup })}\right]=$ $\left[\theta_{3}\right]$.

BET combines all PDFs at each nodes to get the probability of each events. The PDF of the probability of a $k$ type eruption occur in the time interval $\left(t_{0}, t_{0}+\tau\right]$ at the jth vent location, i.e., $\Phi_{1}$, is

$\left[\Phi_{1}\right]=\left[\theta_{1}\right]\left[\theta_{2}\right]\left[\theta_{3}\right]\left[\theta_{4}^{(\mathrm{j})}\right]\left[\theta_{5}^{(\mathrm{k})}\right]$

The probability of having eruption at any location, i.e., $\Phi_{2}$, is

$\left[\Phi_{2}\right]=\sum_{j=1}^{M} \quad\left[\theta_{1}\right]\left[\theta_{2}\right]\left[\theta_{3}\right]\left[\theta_{4}^{(\mathrm{j})}\right]\left[\theta_{5}{ }^{(\mathrm{k})}\right]$

\subsection{Parameter of Mount Merapi Activity}

Volcano status or volcano warning scheme in Indonesia are classified into four phases, i.e. "Normal", "Alert", "Standby" and "Caution" [8]. The status was determined by several parameters have been observed. Normal status is a condition where volcanic activity is normal and does not show any increase in activity based on visual observations, or instrumental research results. Alert status is a condition that show increase in seismic activity and other volcanic events. This light changes in activity caused by magma, tectonic and hydrothermal activity. While Standby status happen if there are intensive increase of seismic activities that indicates that the volcano moving toward eruption. Caution Status indicates that the volcano is immediate or erupting or there is a critical state of disaster.

Table 1 show the parameter and value limit that being observed to determine the status of Mount Merapi according to Center for Research and Technological Development Geology Disaster [8].

Table 1 Parameter of status determination of Mount Merapi

\begin{tabular}{|c|c|c|}
\hline Status & Parameter & Value Limit \\
\hline Normal & Swarm & None \\
\cline { 2 - 3 } & Deformation rate & $0-0,3 \mathrm{~mm}$ day-1 \\
\cline { 2 - 3 } & $\mathrm{CO} 2$ & $5-10 \% \mathrm{~mol}$ \\
\cline { 2 - 3 } & $\mathrm{SO} 2$ & $0-1 \% \mathrm{~mol}$ \\
\cline { 2 - 3 } & $\mathrm{H} 2 \mathrm{~S}$ & $0-1 \% \mathrm{~mol}$ \\
\cline { 2 - 3 } & $\mathrm{HCl}$ & $0-0,3 \% \mathrm{~mol}$ \\
\cline { 2 - 3 } & $\mathrm{NH} 3$ & $0-1,5 \% \mathrm{~mol}$ \\
\cline { 2 - 3 } & Volcanic Earthquake & None \\
\cline { 2 - 3 } & Multi-Phases Earthquake & None \\
\cline { 2 - 3 } & Low-Frequence Earthquake & None \\
\cline { 2 - 3 } & Earthquake Avalanches & None \\
\cline { 2 - 3 } & Pyroclastic flows & None \\
\cline { 2 - 3 } & RSAM & None \\
\hline Alert & Swarm & Exist \\
\cline { 2 - 3 } & Deformation rate & mm/ day \\
\cline { 2 - 3 } & & \\
\cline { 2 - 3 } & & \\
\hline
\end{tabular}




\begin{tabular}{|c|c|c|}
\hline Status & Parameter & Value Limit \\
\hline Standby & $\mathrm{CO} 2$ & $>10 \% \mathrm{~mol}$ \\
\cline { 2 - 3 } & $\mathrm{SO} 2$ & $>1 \% \mathrm{~mol}$ \\
\cline { 2 - 3 } & $\mathrm{H} 2 \mathrm{~S}$ & $>1 \% \mathrm{~mol}$ \\
\cline { 2 - 3 } & $\mathrm{HCl}$ & $>1,5 \% \mathrm{~mol}$ \\
\cline { 2 - 3 } & $\mathrm{NH} 3$ & $<80 \% \mathrm{~mol}$ \\
\cline { 2 - 3 } & $\mathrm{H} 2 \mathrm{O}$ & $>1$ event/ day \\
\cline { 2 - 3 } & Volcanic Earthquake & $>25$ event/ day \\
\cline { 2 - 3 } & Multi-Phases Earthquake $/$ day \\
\hline \multirow{5}{*}{ Caution } & Volcanic Earthquake & Exist \\
\cline { 2 - 3 } & Multi-Phases Earthquake & $>25$ event/ day \\
\cline { 2 - 3 } & Low-Frequence Earthquake & Exist \\
\cline { 2 - 3 } & Earthquake Avalanches & Exist \\
\cline { 2 - 3 } & Pyroclastic flows & \\
\cline { 2 - 3 } & RSAM &
\end{tabular}

\subsection{Historical data of Mount Merapi Eruption}

Based on observation of Mount Merapi from 1961 to 2010, Merapi has recorded 146 times in unrest condition. For 146 times, has recorded 55 periods caused magmatic activity. In an eruption, Mount Merapi erupted as long as 2 until 3 months. From 1780, Merapi erupted 57 times with average rest period between eruption 3-5 years and average scale of eruption in VEI (Volcanic Explosivity Index) is VEI 2. Table 2 show historical data of Merapi eruptions.

Table 2. Historical data of Merapi eruptions

\begin{tabular}{|c|c|c|}
\hline Year of Eruption & Rest Period (Year) & VEI \\
\hline 1786 & 18 & 1 \\
\hline 1791 & 5 & 2 \\
\hline 1797 & 6 & 1 \\
\hline 1807 & 10 & 1 \\
\hline 1810 & 3 & 1 \\
\hline 1812 & 2 & 1 \\
\hline 1822 & 10 & 4 \\
\hline 1832 & 10 & 3 \\
\hline 1837 & 5 & 2 \\
\hline 1840 & 3 & 1 \\
\hline 1846 & 6 & 3 \\
\hline 1849 & 3 & 3 \\
\hline 1861 & 12 & 2 \\
\hline 1862 & 1 & 2 \\
\hline 1865 & 3 & 2 \\
\hline 1872 & 7 & 4 \\
\hline 1878 & 6 & 2 \\
\hline 1883 & 5 & 1 \\
\hline 1885 & 2 & 1 \\
\hline
\end{tabular}

\begin{tabular}{|c|c|c|}
\hline Year of Eruption & Rest Period (Year) & VEI \\
\hline 1888 & 3 & 2 \\
\hline 1889 & 1 & 1 \\
\hline 1891 & 2 & 2 \\
\hline 1897 & 6 & 2 \\
\hline 1902 & 5 & 2 \\
\hline 1905 & 3 & 2 \\
\hline 1907 & 2 & 1 \\
\hline 1909 & 2 & 1 \\
\hline 1915 & 6 & 1 \\
\hline 1920 & 5 & 2 \\
\hline 1924 & 4 & 1 \\
\hline 1925 & 1 & 1 \\
\hline 1930 & 5 & 3 \\
\hline 1933 & 3 & 2 \\
\hline 1935 & 2 & 2 \\
\hline 1939 & 4 & 2 \\
\hline 1942 & 3 & 2 \\
\hline 1948 & 6 & 2 \\
\hline 1949 & 1 & 2 \\
\hline 1953 & 4 & 1 \\
\hline 1954 & 1 & 1 \\
\hline 1956 & 2 & 2 \\
\hline 1957 & 1 & 1 \\
\hline 1961 & 4 & 3 \\
\hline 1967 & 6 & 2 \\
\hline 1969 & 2 & 2 \\
\hline 1972 & 3 & 2 \\
\hline 1976 & 4 & 2 \\
\hline 1980 & 4 & 2 \\
\hline 1986 & 6 & 2 \\
\hline 1994 & 8 & 2 \\
\hline 2001 & 7 & 2 \\
\hline 2010 & 9 & 4 \\
\hline
\end{tabular}

\section{Data Processing}

Data processing have done by using BET_EF/ Bayesian Event Tree for Eruption Forecasting software that being developed by [3]. Each steps of data input were performed sequentially according to the nodes.

\subsection{Data Input for Node 1}

Starting from 1961 to 2010, Mount Merapi is actively monitored for 146 months from a total of 600 months of observation. Parameters monitored at node 1 are early warning parameters at alert level, i.e. swarm (small earthquake sequence) and also deformation rate from lava 
dome formation. Figure 1. shows the input process on Node 1.

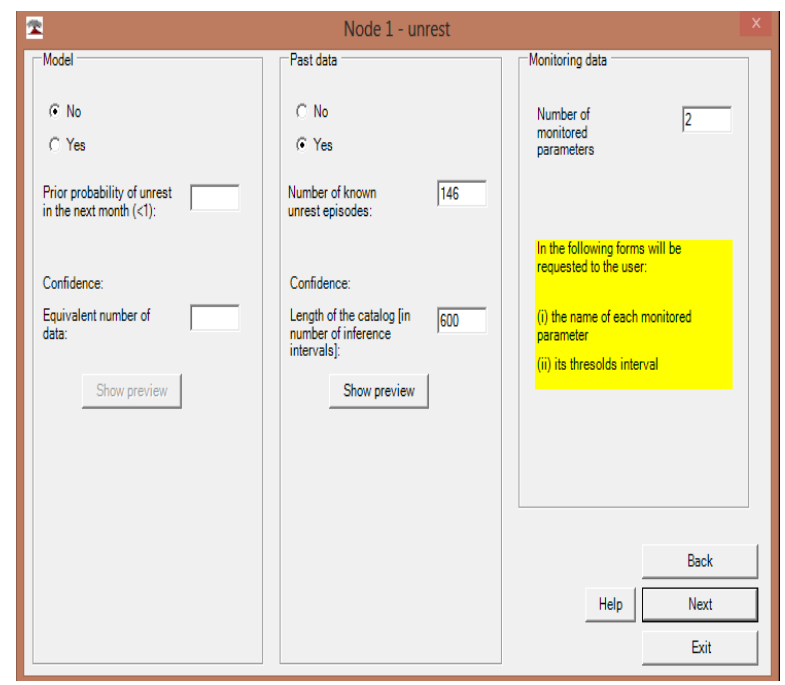

Fig. 1 Data Input for Node 1

\subsection{Data Input for Node 2}

Mont Merapi is observed as active caused by magmatic activity of 55 months from a total of 146 months of active states. The parameters monitored at node 2 are early warning parameters at the standby level, i.e. volcanic gas content $(\mathrm{CO} 2, \mathrm{SO} 2, \mathrm{H} 2 \mathrm{~S}, \mathrm{HCl}, \mathrm{NH} 3)$, water content $(\mathrm{H} 2 \mathrm{O})$, volcanic earthquakes, and multi-phases earthquakes. Figure 2. Describes data input for node 2.

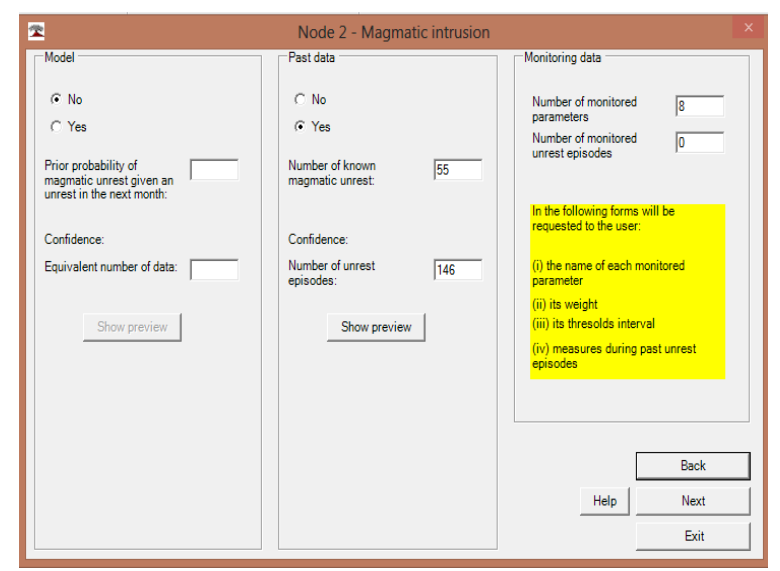

Fig. 2. Data Input for Node 2

\subsection{Data Input for Node 3}

The required data in this stage is how many observed eruptions in a matter of months from the total of Mount Merapi is actively monitored due to the magmatic activity and the parameters monitored at the early warning level. Counted Mount Merapi monitored eruption as much as 46 months from a total of 55 months of active Merapi observed as magmatic activity. Parameters monitored in Node 3 are early warning parameters at standby level, i.e. volcanic earthquakes, multi-phases earthquakes, low- frequency earthquakes, falling earthquakes, hot clouds, and RSAM (Realtime Seismic Amplitude Measurement). In Figure 3. the data input for Node 3 is given.

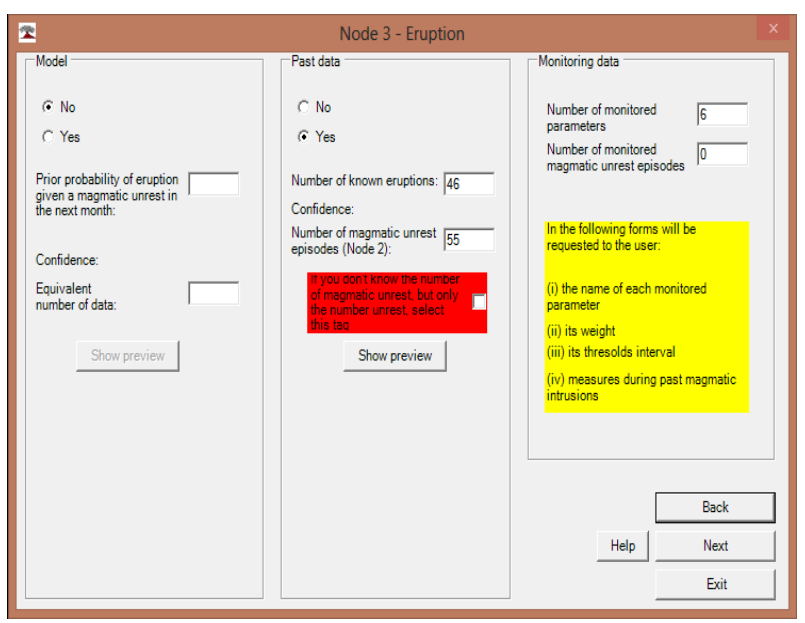

Fig. 3 Data Input for Node 3

\subsection{Data Input for Node 4}

At this node the required data are the central coordinates of Mount Merapi, the radius of the eruption range, the direction of the next eruption, and the historical data of the location of the eruption. Based on the Center for Volcanology and Geological Hazard Mitigation, Mount Merapi lies at 7032'30 "LS and 110026'30" BT. If converted to Universal Transverse Mercator (UTM) unit Mount Merapi lies $9166432.32 \mathrm{~m}$ at latitude and $438908.54 \mathrm{~m}$ at longitude. The closest range radius is 5 $\mathrm{km}$ while the most distant radius is $17 \mathrm{~km}$. The eruption data from 1961-2010 shows that the eruption always appears in the central crater which means it is located at location 1.

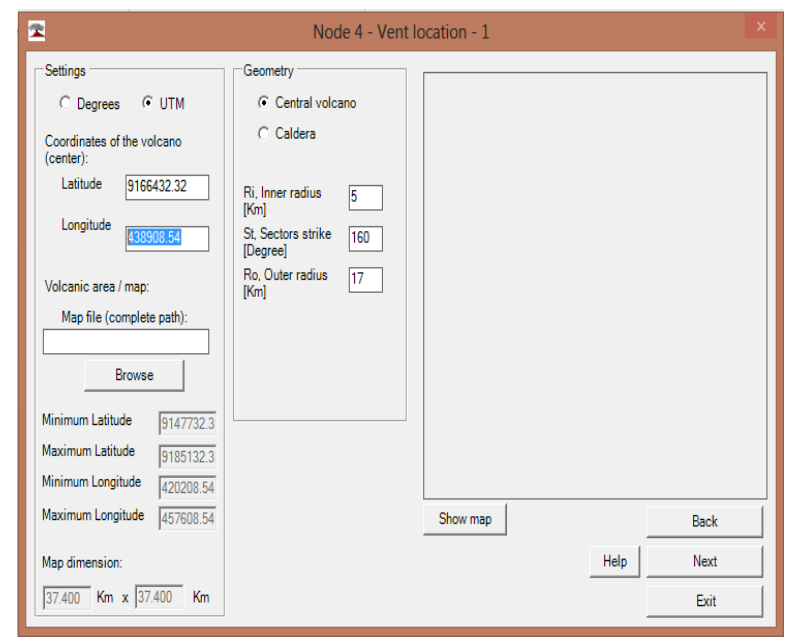

Fig. 4. Data Input for Node 4 


\subsection{Data Input for Node 5}

The required data on this node is the historical data of eruption size (VEI) of Mount Merapi. Figure 5. shows the input of Node 5 for VEI 1. Input for Node 5 is then performed for each VEIs according to the eruption frequency at each VEIs.

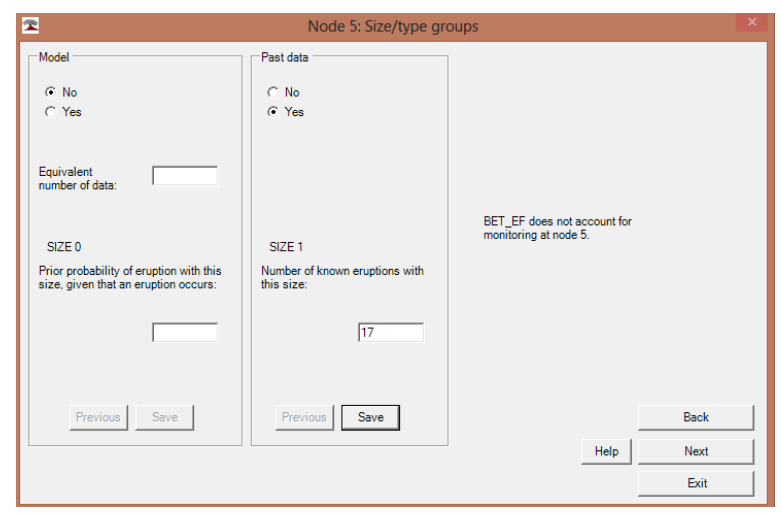

Fig. 5. Data Input for Node 5

\section{Result and Discussion}

The result is shown in Figure 6, Figure 7 and Figure 8. Figure 6 shows the probability of Merapi eruption in the future is 0,82 . After getting probability of Merapi eruption, we can get the probability of the location of the next eruption as shown in Figure 7 . There are 5 locations that probably being center of eruption.

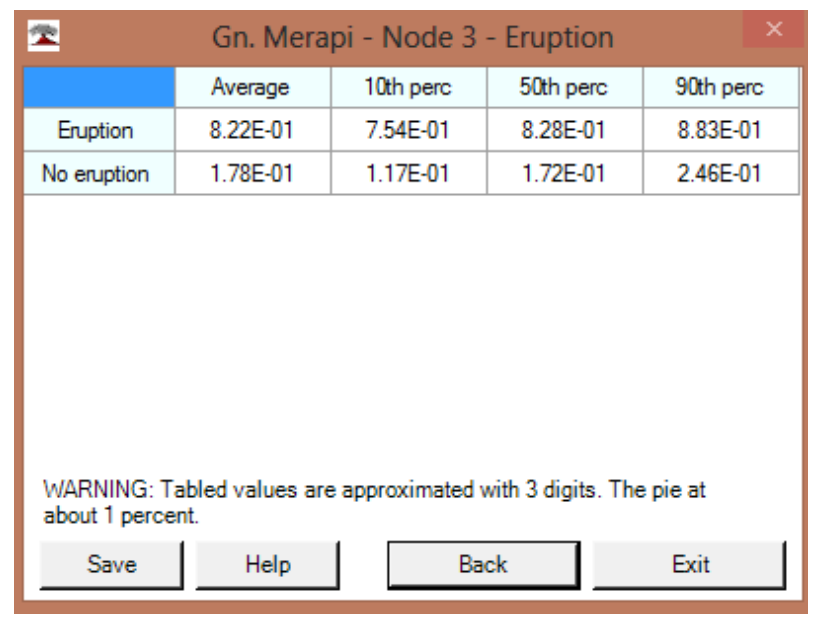

Fig. 6. The probability of Mount Merapi eruption

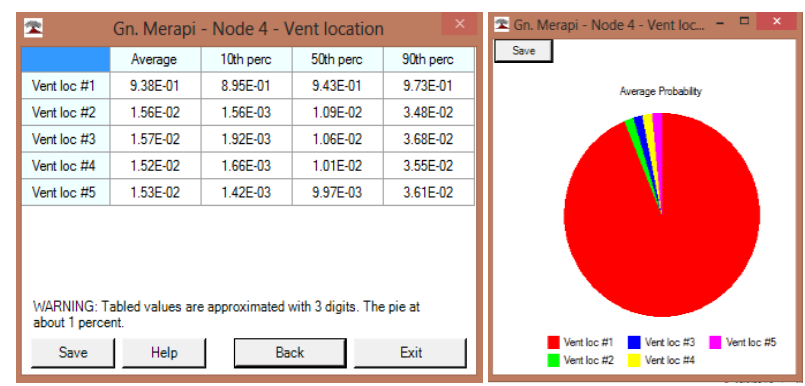

Fig 7. The probability of Mount Merapi Eruption Location
The purpose of predicting eruption's size is to know the future size of the eruption so we can determine which area that will be affected by the eruption of Merapi. As has been stated in the regulation of Ministry of Human Resources No. 15 year 2011 about Mitigation Guidelines of Volcano Disaster, Ground Movement, and Tsunami, disaster-prone zone is divided into three zone: Disasterprone Zone I, Disaster-prone Zone II, and Disaster-prone Zone 3. Disaster-prone Zone I is $17 \mathrm{Km}$ from the central of eruption. Disaster-prone Zone II is $10 \mathrm{Km}$ from the center of eruption. While Disaster-prone Zone III is $5 \mathrm{Km}$ from the center of eruption. The size of the eruption determines which areas affected by Mount Merapi's eruption and the safe zone from the eruption. The 2010 eruption was a high level eruption with VEI of 4 , so the government of Sleman did not impose the Disaster-prone zone regulation, hence Disaster-prone Zone I became a dangerous zone too. Therefore, the government of Sleman set the safe radius as $30 \mathrm{Km}$ seeing how big the eruption was in 2010. The size of the future eruption can affect which areas will be affected by it, so the related parties can make a decision regarding safe zone. Software BET_EF measures the eruption size in future VEI units. Figure 5 shows the output software that shows the probability of every future VEI. In Figure 8, it can be seen that the biggest probability is VEI 2 and the smallest probability is VEI 4.

\begin{tabular}{|c|c|c|c|c|}
\hline 2 & \multicolumn{3}{|c|}{ Gn. Merapi - Node 5 - Sizes } & > \\
\hline & Average & 10th perc & 50 th perc & 90th perc \\
\hline Size 1 & $2.88 \mathrm{E}-01$ & $2.18 \mathrm{E}-01$ & $2.84 \mathrm{E}-01$ & $3.64 \mathrm{E}-01$ \\
\hline Size 2 & $5.49 \mathrm{E}-01$ & 4.69E-01 & $5.46 \mathrm{E}-01$ & $6.31 \mathrm{E}-01$ \\
\hline Size 3 & $9.68 \mathrm{E}-02$ & $5.23 \mathrm{E}-02$ & 9.15E-02 & $1.46 \mathrm{E}-01$ \\
\hline Size 4+ & 6.61E-02 & 2.76E-02 & 6.19E-02 & $1.11 \mathrm{E}-01$ \\
\hline \multicolumn{5}{|c|}{$\begin{array}{l}\text { WARNING: Tabled values are approximated with } 3 \text { digits. The pie at } \\
\text { about } 1 \text { percent. }\end{array}$} \\
\hline Save & Help & \multicolumn{2}{|c|}{ Back } & Exit \\
\hline
\end{tabular}

Fig. 3 The probability of eruption size

Based on the data processing using software BET_EF, it shows a probability with beta distribution for every possible size of future eruption. VEI 1 has probability of 0,288 . VEI 2 has probability of 0,549. VEI 3 has probability of 0,097 . VEI 4 has probability of 0,066 . It can be seen from the output software BET_EF that VEI 2 probability is the highest, so it can be concluded that the level of the next eruption will be the same as VEI 2 level. This is supported by historical data and the characteristics of Merapi Mount that big eruption will occur once every 30-40 years and after that happens, the magma chamber will be emptied and needs time to make another big eruption.

If the next eruption is the same level as VEI 2, it is estimated that Disaster-prone Zone II and some parts of Disaster-prone Zone I will be affected. By seeing the Hazard Map, the areas that will be affected by the eruption 
are Ngemplak, Tempel, Turi, Pakem, and Cangkringan districts. From these 5 districts, there are 21 villages that are estimated to be affected by the eruption. The choosing of affected areas is also based on the morphology of Merapi Mount, which the eruption is estimated to be going to these 5 districts.

\section{Conclusion}

The result of the data processing shows that Merapi will erupt again in the future with the probability of 0,822 . The eruption will be take place in the main crater of Merapi with the probability of 0,938 . The next eruption will have the power of VEI 2 with the probability of 0,549 .

In accordance with the data processing using software BET_EF that predicts the location of eruption (main crater) with the power VEI 2, the areas that will be affected by the eruption are Disaster-prone Zone I and Disaster-prone Zone II with the radius of $17 \mathrm{Km}$ from the center of the eruption and directed 1600 from the north, which is Sleman. Ngemplak and Tempel are in Disasterprone Zone I, while Turi, Pakem, and Cangkringan are in Disaster-prone Zone II. So, it can predict the five districts that will be affected by the Merapi eruption.

\section{Future Work}

After getting prediction of Mount Merapi eruption involve the location and size of the next disaster we will design preparedness in humanitarian logistic based on eruption forecasting.

\section{References}

1. A. Cozzolino, Humanitarian Logistics: Cross-sector Cooperation in Disaster Relief Management, Springer, Heidelberg (2012)

2. G. O'Brien, P. O'Keefe, Z. Gadema, J. Swords, "Approaching disaster management through social learning", Disaster Prevention and Management, 19 498-508 (2010)

3. W. Marzocchi, L. Sandri, J. Selva, "BET EF: a probabilistic tool for long- and short-term eruption forecasting", Bull Volcano, 80, 623-632 (2008)

4. A. Garcia-Aristizabal, J. Selva, E. Fujita, "Integration of stochastic models for long-term eruption forecasting into a Bayesian event tree scheme: a basis method to estimate the probability of volcanic unrest", Bulletin of Volcanology, 75, 689 (2013)

5. A. Gelman, J.B. Carlin, H.S. Stern, D. B. Rubin, Bayesian data analysis. CRC, Boca Raton, FL (1995)

6. E. M. Fournier d'Albe, Objectives of volcanic monitoring and prediction. Journal of the Geological Society London, 136, 321-326 (1979)

7. W. Marzocchi, L. Sandri, P. Gasparini, C. Newhall, E. Boschi, Quantifying probabilities of volcanic events: the example of volcanic hazard at Mt. Vesuvius. J Geophys Res 109 (2004)

8. “_, "Balai Penyelidikan dan Pengembangan Teknologi Kebencanaan Geologi, 2014 